\title{
Pelatihan Kader Lansia Dalam Upaya Peningkatan Pelayanan Kesehatan Lansia Pada Keluarga
}

\author{
Khusnul Nikmah*, Mila Khomsatun \\ Sekolah Vokasi Prodi D III Kebidanan Universitas Islam Lamongan, Indonesia \\ *khusnulnikmah.80@gmail.com
}

\begin{abstract}
ABSTRAK
Meningkatnya jumlah lansia seiring dengan penyakit yang diderita lansia. Menurunnya kondisi fisik, psikologis, dan sosial yang dialami lansia sehingga lansia harus tinggal bersama keluarga. Jika keluarga tidak bisa merawat lansia dengan baik maka lansia akan terabaikan sehingga keluarga perlu memberikan dukungan kepada lansia. Keluarga perlu diberikan pelatihan sehingga keluarga tahu, paham dan dapat memberikan pelayanan ketika mendampingi lansia. Agar materi yang disampaikan dapat berkelanjutan sebelum keluarga diberikan pelatihan terlebih dahulu diberikan pelatihan kepada kader sebagai pendamping tenaga kesehatan. Tujuan pengabdian masyarakat adalah meningkatkan pengetahuan dan pemahaman keluarga tentang pelayanan kesehatan lansia. Metode pelatihan yang diberikan melalui ceramah dan tanya jawab, diskusi, dan demonstrasi uji keterampilan fisik tentang cara perawatan dasar pada lansia di rumah. Alat bantu yang digunakan modul, LCD proyektor, dan buku catatan. Hasil pelatihan didapatkan antusias serta keterampilan kader dan keluarga tentang pelayanan kesehatan lansia. Keterampilan yang didapat yaitu keterampilan perawatan demam pada lansia, pengukuran aktifitas fisik lansia, pengukuran aktifitas sosial lansia, dan pengukuran keseimbangan tubuh lansia.
\end{abstract}

Kata Kunci: Peningkatan Pelayanan Kesehatan, Lansia, Keluarga, Kader

Received: June 28, 2020

Revised: July 18,2020

Accepted: August 22, 2020

This is an open-acces article distributed under the terms of the Creative Commons Attribution-ShareAlike 4.0 International License.

\section{PENDAHULUAN}

Lansia merupakan salah satu kelompok atau populasi berisiko (population at risk) yang semakin meningkat jumlahnya. Allender, Rector, dan Warner (2014) mengatakan bahwa populasi berisiko (population at risk) adalah kumpulan orang-orang yang masalah kesehatannya memiliki kemungkinan akan berkembang lebih buruk karena adanya faktor-faktor risiko yang mempengaruhi. Stanhope dan Lancaster (2016) mengatakan lansia sebagai populasi berisiko ini memiliki tiga karakteristik risiko kesehatan yaitu, risiko biologi termasuk risiko terkait usia, risiko sosial dan lingkungan serta risiko perilaku atau gaya hidup. Indonesia mengalami peningkatan jumlah penduduk lansia dari 18 juta jiwa $(7,56 \%)$ pada tahun 2010 , menjadi 25,9 juta jiwa $(9,7 \%)$ pada tahun 2019, dan diperkirakan akan terus meningkat dimana tahun 2035 menjadi 48,2 juta jiwa $(15,77 \%)$. Dampak dari terjadinya populasi yang menua yaitu makin besarnya proporsi lansia terhadap jumlah penduduk di suatu negara. Indonesia saat ini sudah menuju 
kepada kondisi populasi menua dengan persentase Lansia sebesar 9,7\% sedangkan negara- negara maju sudah melebihi $10 \%$ bahkan Jepang sudah melebihi $30 \%$ (Kemenkes, 2019).

Meningkatnya jumlah lansia perlu diperhatikan kebutuhan lansia sehingga lansia tetap sehat, mandiri, aktif, dan produktif. Berdasarkan data Riskesdas tahun 2018, penyakit yang terbanyak pada lansia adalah untuk penyakit tidak menular antara lain : hipertensi, masalah gigi, penyakit sendi, masalah mulut, diabetes mellitus, penyakit jantung dan stroke, dan penyakit menular antara lain seperti ISPA, diare, dan pneumonia. Jumlah orang dengan demensia cenderung meningkat seiring dengan meningkatnya kasus penyakit tidak menular. Kondisi tersebut akan berdampak pada kondisi ketergantungan lansia akan bantuan orang lain, terutama keluarga. Dari hasil penilaian tingkat kemandirian dengan menggunakan instrumen Activity Daily Living (ADL), terdapat $74,3 \%$ lansia mandiri yang berpeluang untuk dioptimalkan potensinya, agar berkontribusi di masyarakat dan lingkungannya. Sebaliknya lansia dengan ketergantungan sedang, berat, dan total sebanyak 3,7\%, dengan penyebab utama adalah penyakit stroke, cedera, rematik dan kencing manis (Riskesdas, 2018)

Menurut Sulastri (Sulastri \& Humaedi, 2017) terdapat alasan keluarga tidak dapat memberikan dukungan sosial kepada lansia yaitu : 1) Nilai - nilai kekeluargaan sudah mulai luntur, lansia dianggap beban dan keluarga cenderung memperhatikan keluarga inti tanpa memperhatikan kebutuhan keluarga besar. 2) Kesibukan karena bekerja, anakanak memiliki pekerjaan yang menuntut waktu yang banyak sehingga tidak punya waktu yang cukup untuk merawat orang tua. Perubahan tanggung jawab keluarga dalam merawat lansia membuat hidup lansia tidak potensial dan menjadi terlantar atau menjadi terabaikan di keluaga.

Dampak populasi lansia yang meningkat di suatu wilayah bersamaan dengan meningkatnya jumlah penelantaran lansia di masyarakat yaitu meningkatnya angka rasio ketergantungan hidup (old dependency ratio). Rasio ketergantungan hidup lansia meningkat dari $12,2 \%$ pada tahun 2005 menjadi 13,3\% pada tahun 2009, dan saat ini meningkat menjadi 48,63\% (Kemenkes, 2019). Jika tidak segera ditangani maka terdapat kecenderungan meningkatnya penduduk lansia terlantar yang tidak mendapat dukungan untuk memenuhi kebutuhan dasar hidup mereka. Lansia perlu diberikan dukungan oleh keluarga melalui pemberian dukungan keluarga, melaksanakan 5 tugas kesehatan keluarga pada lansia, dan keluarga melaksanakan hubungan sosial dan aktifitas sosial pada lansia (social engagement). Hal ini perlu tindakan segera untuk mengatasi masalah melalui pemberian pelatihan kepada masyarakat yaitu keluarga.

Pendidikan kesehatan melalui pelatihan penting diberikan kepada keluarga dengan tujuan untuk memberdayakan keluarga dan meningkatkan rasa percaya diri serta kompetensi keluarga dalam merawat lansia, dengan meningkatnya pengetahuan keluarga maka akan menimbulkan rasa tanggung jawab dalam mendampingi lansia sehingga akan mengurangi perasaan beban dan stress dalam merawat lansia (DiZazzo-Miller, Samuel, Barnas, \& Welker, 2014). Keluarga yang merawat lansia perlu pemahaman awal tentang kondisi lansia dengan respon yang tepat (Alavi, Sail, Idris, Samah, \& Omar, 2011). Melalui pelatihan diharapkan pengetahuan dan keterampilan keluarga dalam merawat lansia dapat diaplikasikan (DiZazzo-Miller et al., 2014) . Keluarga sebagai pelaku rawat utama perlu diberdayakan dengan memberikan pengetahuan dan keterampilan melalui pelatihan. Hasil penelitian menunjukkan bahwa pengabaian lansia banyak dilakukan oleh pemberi asuhan yang kurang pengalaman dan kurangnya pengetahuan (Alavi et al., 2011). 


\section{Journal of Community Engagement in Health}

Pelatihan merupakan bagian dari investasi SDM (human investment) untuk meningkatkan kemampuan dan keterampilan kerja. Pelatihan kader (trainers) bertujuan untuk meningkatkan pengetahuan dan keterampilan kader tentang pengabaian lansia di keluarga dan keterampilan diri untuk melaksanakan tugas baik di posyandu maupun melalui kunjungan rumah (terutama bagi keluarga yang sibuk bekerja di luar rumah). Peran tenaga kesehatan adalah sebagai fasilitator membantu pemenuhan pelayanan sarana dan prasarana kesehatan serta bimbingan tekhnis tenaga kesehatan (Waryana, 2017)

Tujuan dari pelatihan adalah untuk meningkatkan pengetahuan kader dan keluarga tentang peningkatan pelayanan kesehatan lansia pada keluarga dan kemampuan dalam melakukan keterampilan perawatan dasar pada lansia seperti perawatan demam, pengukuran aktifitas fisik, pengukuran aktifitas sosial, dan pengukuran keseimbangan tubuh pada posisi duduk dan berdiri.

\section{METODE}

Pelaksanaan kegiatan dilakukan di Desa Bugel Kecamatan Sekaran Kabupaten Lamongan dengan alasan pelayanan kesehatan Lansia di Desa Bugel masih jauh dari sempurna. Langkah-langkah pemberdayaan dilakukan melalui 4 tahap yaitu: 1) Tahap identifikasi masalah; 2) Tahap pelatihan pada kader; 3) Tahap pelatihan pada keluarga; 4) Monitoring dan evaluasi. Pada tahap identifikasi masalah dilakukan pertemuan dengan camat, lurah, petugas puskesmas, kader dan RW untuk sosialisasi kegiatan dan mengidentifikasi kebutuhan serta tujuan, rencana, dan kegiatan yang dilakukan kemudian melakukan pertemuan dengan pihak puskesmas dan kader untuk melakukan seleksi terhadap keluarga.

Sebelum melakukan pelatihan kepada keluarga, terlebih dahulu dilakukan pelatihan kepada kader (trainers) sebagai pelatih keluarga untuk keberlangsungan model yang dilakukan. Syarat kader menjadi pelatih yaitu aktif dalam kegiatan posyandu, lama kerja minimal 5 tahun, kader minimal tamat SMA, bersedia mengikuti kegiatan dari awal hingga selesai, minimal melakukan kunjungan kepada keluarga sebanyak 12 kali kunjungan. Pelatihan kepada kader dilakukan selama 2 hari. Pelatihan menggunakan modul sebagai bahan pegangan. Hari pertama terdiri atas 4 sesi yaitu untuk menjelaskan tentang Peningkatan Pelayanan Kesehatan Lansia , pada sesi ke dua menjelaskan tentang tugas kesehatan keluarga dan pada sesi ke tiga dan ke empat menjelaskan tentang dukungan keluarga serta hubungan sosial dan aktifitas sosial yang dapat dilakukan keluarga kepada lansia. Pada hari ke dua adalah pemberian pelatihan tentang uji keterampilan fisik tentang perawatan dasar yang diberikan kepada lansia. Keterampilan dasar yang diberikan kepada kader adalah; 1) Cara mengatasi demam; 2) Cara mengukur kemampuan lansia dalam melakukan aktifitas (barthel indeks) yaitu : ke kamar mandi, mandi, berpakaian, berpindah tempat, makan, dan BAB/BAK; 3) Cara mengukur fungsi keluarga dalam melakukan aktifitas sosial lansia; 4) Cara mengukur kemampuan lansia dalam menjaga keseimbangan tubuh dalam posisi duduk dan berdiri. Pelatihan dilakukan oleh peneliti, masing-masing sesi menggunakan waktu 60 menit.

Pelatihan kepada keluarga disampaikan oleh kader dengan kriteria utama : keluarga tinggal bersama lansia, keluarga sebagai pelaku rawat utama lansia, bisa membaca dan menulis, keluarga dengan lansia yang tidak tirah baring, bersedia mengikuti kegiatan dari awal sampai akhir kegiatan. Pelatihan dilakukan selama 2 hari dengan materi yang sama saat pelatihan kader dimana untuk keluarga adalah tentang cara perawatan lansia oleh pelaku rawat yaitu keluarga. 


\section{Journal of Community Engagement in Health}

Pada awal pertemuan pelatihan kepada keluarga dilakukan refleksi diri untuk memberikan kesadaran kepada keluarga yaitu bagaimana pengalaman dan strategi koping yang dilakukan saat merawat lansia, menggali perasaan yang dirasakan ketika merawat dan saling berbagi dengan anggota yang lain (Bigala \& Ayiga, 2014). Hal ini bertujuan agar masing-masing keluarga sebagai kelompok pendukung tidak merasa sendiri tapi masih memiliki teman yang dapat saling mendiskusikan aspek positif dan negatif dari situasi yang dialami untuk mendiskusikan masalah secara terbuka sehingga diharapkan dapat berpartisipasi aktif ketika pelatihan dilaksanakan (McDonald \& Thomas, 2013). Pada akhir setiap sesi materi kepada peserta diberikan pertanyaan dan untuk menjawab pertanyaan diberi kesempatan kepada peserta lain untuk menjawab. Untuk evaluasi demonstrasi kepada peserta disuruh memperagakan keterampilan yang sudah diperoleh.

\section{HASIL}

Di Desa Bugel Kecamatan Sekaran Kabupaten Lamongan peningkatan kesehatan lansia merupakan salah satu kegiatan dalam organisasi kegiatan kesejahteraan keluarga melalui pemanfaatan pelayanan kesehatan adalah peran kader. Kader sebagai penggerak masyarakat tidak hanya dilibatkan dalam pengetahuan tentang kesehatan lansia tetapi pengetahuan tentang meningkatkan kualitas lansia melalui peran keluarga sehingga lansia tidak terabaikan. Keluarga perlu mengetahui tentang cara merawat lansia melalui pemberian dukungan ke lansia baik dukungan informasi, dukungan instrumental, dukungan emosional, dan dukungan penghargaan. Selain itu keluarga juga harus tahu tentang tugas kesehatan keluarga ketika lansia mengalami perubahan kondisi seperti mengenal masalah yang dialami lansia, mengambil keputusan secara cepat, melakukan perawatan ketika lansia sakit, memberikan lingkungan yang nyaman, dan memanfaatkan fasilitas lingkungan untuk kesehatan lansia melalui senantiasa berhubungan sosial dan melakukan aktifitas sosial (social engagement) (Punyakaew, Lersilp, \& Putthinoi, 2019). Semua ini akan terlaksana melalui pendekatan yang dilakukan oleh kader dengan melakukan pertemuan rutin antara lansia dan keluarga melalui kunjungan ke posyandu.

Tabel. Karakteristik Kader di Desa Bugel Kecamatan Sekaran Kabupaten Lamongan.

\begin{tabular}{llcc}
\hline No & Karakteristik & Jumlah & Peresentase [\%] \\
\hline 1 & Usia & & \\
& $40-45$ & 3 & 60 \\
& $46-50$ & 2 & 40 \\
\hline 2 & Pekerjaan & & \\
& Bekerja Tidak & 0 & 0 \\
& bekerja & 100 & 100 \\
\hline 3 & Pendidikan & & \\
& SMA & 4 & 83 \\
& PT & 1 & 17 \\
\hline & Jumlah & 6 & 100 \\
\hline
\end{tabular}




\section{Journal of Community Engagement in Health}

Tabel 2. Karakteristik Keluarga di Desa Bugel Kecamatan Sekaran Kabupaten Lamongan.

\begin{tabular}{llrc}
\hline No & Karakteristik & Jumlah & Peresentase [\%] \\
\hline 1 & Usia & & \\
& $25-35$ & 11 & 44 \\
& $36-45$ & 10 & 40 \\
& $46-55$ & 4 & 16 \\
\hline 2 & Pekerjaa & & \\
& Bekerja Tidak & 16 & 64 \\
& bekerja & 9 & 36 \\
\hline 3 & Pendidikan & & \\
& SMA & 21 & 84 \\
& PT & 4 & 16 \\
\hline 4 & Jenis Kelamin & & \\
& Laki-laki & 6 & 24 \\
& Perempuan & 19 & 76 \\
\hline & Jumlah & 25 & 100
\end{tabular}

Berdasarkan tabel 1 dari 5 orang kader yang dilatih berdasarkan usia didapatkan pra lansia 3 orang dan lansia 2 orang. Ditinjau dari pekerjaan didapatkan kader tidak bekerja semua, dan ditinjau dari tingkat pendidikan rata rata berpendidikan SMA hanya satu orang yang berpendidikan tinggi.

Berdasarkan tabel 2 didapatkan usia pelaku rawat lansia paling banyak berada pada rentang dewasa awal dan dewasa akhir, banyak yang bekerja (64\%) dan 76\% pelaku rawat yaitu perempuan.

\section{PEMBAHASAN}

Berdasarkan wawancara awal dengan keluarga didapatkan beberapa keluarga mempunyai lansia yang berpenyakit menahun dan merawat orang tua sama pentingnya dengan bekerja mencari nafkah, namun ada beberapa keluarga yang harus berhenti bekerja untuk lebih fokus merawat orang tua. Terdapat pula keluarga yang berfikir untuk menempatkan lansia ke perawatan jangka panjang atau panti jompo karena secara finansial, fisik, dan emosional tidak dapat merawat orang tua. Pengabaian lansia dapat diawali dengan ketegangan dan kelelahan keluarga dalam merawat anggota keluarga inti yang bersamaan dengan lansia yang tinggal bersama. Pelatihan yang di berikan kepada keluarga membantu keluarga untuk mengimplementasikan perubahan melalui pertemuan dengan sesama peserta melalui aktifitas kelompok seperti berbagi pengetahuan, kerampilan koping, memahami orang lain dan berbagi pengalaman dalam merawat lansia. Pada awal pertemuan kepada peserta dilakukan refleksi diri untuk memberikan kesadaran yaitu bagaimana pengalaman dan strategi koping yang digunakan saat merawat lansia, menggali perasaan yang dirasakan ketika merawat lansia dan saling berbagi dengan anggota yang lain. Hal ini bertujuan agar masingmasing peserta tidak merasa sendiri tapi masih memiliki teman yang dapat saling mendiskusikan aspek positif dan negatif dari situasi yang dialami. Pada proses pelaksanaan keluarga nampak sedih dari situasi yang dihadapi berdasarkan pengalaman ketika mendampingi lansia. Dan berusaha untuk memahami dan menerima keadaan lansia. 


\section{Journal of Community Engagement in Health}

Materi yang disampaikan kepada peserta menggunakan modul sebagai bahan pegangan. Materi yang diberikan adalah tentang dukungan keluarga kepada lansia (dukungan informasi, dukungan emosional, dukungan instrumental, dan dukungan penghargaan), pelaksanaan tugas kesehatan kepada anggota keluarga (mengenal masalah, mengambil keputusan yang tepat, mampu merawat anggota yang sakit, memanfaatkan lingkungan rumah yang menunjang kesehatan, dan memanfaatkan pelayanan kesehatan di lingkungan tempat tinggal. Setiap satu sesi materi kepada peserta diberi kesempatan untuk memberikan pertanyaan dan jawaban di diskusikan secara bersama berdasarkan pengalaman yang dialami masing-masing peserta. Peserta nampak bersemangat menceritakan pengalamannya dan antusias dalam mendengarkan pengalaman yang disampaikan peserta.

Peningkatan pelayanan kesehatan terhadap lanjut usia diperlukan untuk mewujudkan lansia yang sehat, berkualitas, dan produktif di masa tuanya. Pelayanan kesehatan pada lansia harus diberikan sejak dini yaitu pada usia pra lansia (45-59 tahun). Pembinaan kesehatan yang dilakukan pada lansia yaitu dengan memperhatikan faktorfaktor risiko yang harus dihindari untuk mencegah berbagai penyakit yang mungkin terjadi. Kemudian perlu juga memperhatikan faktor-faktor protektif yang dilakukan untuk meningkatkan kesehatan lansia. Upaya yang telah dilakukan di Indonesia untuk meningkatkan pelayanan kesehatan pada lansia antara lain pelayanan geriatri di rumah sakit, pelayanan kesehatan di puskesmas, pendirian home care bagi lansia yang tidak bisa melakukan kegiatan sama sekali (berkebutuhan khusus) dan adanya Pos Pelayanan Terpadu (Posyandu) Lanjut Usia atau Pos Pembinaan Terpadu (Posbindu). Pelayanan kesehatan ini tidak hanya memberikan pelayanan pada pada upaya kuratif, melainkan juga menitikberatkan pada upaya promotif dan preventif. Berbagai pelayanan kesehatan tersebut, diharapkan dapat meningkatkan kualitas hidup.

Keluarga wajib memberikan perawatan kepada lansia (Khanal, Rai, \& Chalise, 2018). Pada saat pelatihan kepada keluarga yang merawat lansia juga diajarkan keterampilan dasar dalam perawatan lansia di rumah dengan menggunakan modul sebagai pegangan. Keterampilan yang diajarkan meliputi: 1) Mengatasi demam memalui kompres; 2) Cara mengukur kemampuan lansia dalam melakukan aktifitas fisik (bartel indeks) yaitu kemampuan berjalan ke kamar mandi, kemampuan mandi, berpakaian, berpindah tempat, makan, dan BAB/BAK; dan 3) Mengukur fungsi keluarga dalam melakukan aktifitas sosial lansia. Setelah keterampilan di demostrasikan oleh pelatih yaitu kader kepada peserta disuruh maju kedepan untuk memperagakan kemampuannya dalam melakukan keterampilan yang telah diperagakan. Peserta nampak antusias dan semangat dalam melakukan demostrasi keterampilan dan berharap bisa menerapkan ketika berhadapan dengan lansia pada situasi yang dihadapi nantinya.

\section{KESIMPULAN}

Topik lansia merupakan isu yang harus di bahas mengingat jumlah lansia yang terus meningkat dari tahun ke tahun. Lansia harus diberdayakan melalui peran keluarga. Dari hasil pelatihan didapatkan para peserta yaitu keluarga dan pelatih yaitu kader (sustainable) bersemangat dan antusias dalam mendengarkan materi dan mendemostrasikan keterampilan yang diperagakan. Saran untuk pengabdian masyarakat selanjutnya dapat melanjutkan pelatihan kepada lansia secara langsung dengan topik tentang kesehatan lansia yang dipadukan dengan keterampilan untuk meningkatkan produktivitas lansia. Hal ini bertujuan agar lansia dapat aktif, produktif, dan mandiri serta yakin akan kemampuan yang 


\section{Journal of Community Engagement in Health}

http://jceh.org

ISSN: 2620-3758 (print); 2620-3766 (online)

https://doi.org/10.30994/jceh.v3i2.66

Vol.3 No.2. Sep 2020. Page.210-216

dimilikinya. Kader sebagai tenaga penggerak masyarakat dapat melanjutkan materi yang sudah di peroleh kepada keluarga yang berada di wilayah kerjanya.

\section{DAFTAR PUSTAKA}

Alavi, K., Sail, R. M., Idris, K., Samah, A. A., \& Omar, M. (2011). Living arrangement preference and family relationship expectation of elderly parents. Pertanika Journal of Social Science and Humanities, 19(SPEC. ISSUE), 65-73.

Allender, J.A., Rector, C., \& Warner, K.D. (2014). Community dan public health nursing promoting the public's health (8th Ed.). Philadelphia: Lippincott Williams \& Wilkins

Bigala, P., \& Ayiga, N. (2014). Prevalence and predictors of elder abuse in mafikeng local municipality in South Africa. Etude de La Population Africaine, 28(1), 463474. https://doi.org/10.11564/28-1-500

BPS. (2015). Statistik Penduduk Lanjut Usia. Badan Pusat Statistik.

DiZazzo-Miller, R., Samuel, P. S., Barnas, J. M., \& Welker, K. M. (2014).

Addressing everyday challenges: Feasibility of a family caregiver training program for people with dementia. American Journal of Occupational Therapy,68(2),212220. https://doi.org/10.5014/ajot.2014.009829

Kemenkes. (2019). Analisis lansia di Indonesia. Pusat Data Dan Imformasi Kemenkes.

Khanal, P., Rai, S., \& Chalise, H. N. (2018). American Journal of Gerontology and Geriatrics Children 's Migration and Its Effect on Elderly People : A Study at Old Age Homes in Kathmandu. (June 2019).

McDonald, L., \& Thomas, C. (2013). Elder abuse through a life course lens. International Psychogeriatrics, 25(8), 1235-1243.

Punyakaew, A., Lersilp, S., \& Putthinoi, S. (2019). Active ageing level and time use of elderly persons in a Thai suburban community. Occupational Therapy International,2019.

https://doi.org/10.1155/2019/7092695

Riskesdas. (2018). Ringkasan Hasil Riset Kesehatan Dasar. Samjana, T. (2017). Abandonment of Elderly People in. 1-40.

Stanhope Lancaster. (2016). Public health nursing: population centered health care in the community. USA Mosby.

Stanhope, M., \& Lancaster, J. (2016). Public health nursing population centered health care in the community (9th Ed.). Missouri: Elsevier.

Sulastri, S., \& Humaedi, S. (2017). Pelayanan Lanjut Usia Terlantar Dalam Panti. Prosiding Penelitian Dan Pengabdian Kepada Masyarakat, 4(1), 155. https://doi.org/10.24198/jppm.v4i1.14225 